\title{
Tuberculosis diagnostic delay and therapy outcomes of non-national migrants in Tel Aviv, 1998-2008
}

Z Mor (zohar.mor@rml.health.gov.il)1, H Kolb², M Lidji3 , G B Migliori4, A Leventhal5,6

1. Department of Tuberculosis and AIDS, Ministry of Health, Jerusalem, Israel

2. Ben Gurion University in the Negev, Beer Sheva, Israel

3. Tel Aviv Tuberculosis Clinic, Israeli Lung Association, Tel Aviv, Israel

4. World Health Organization Collaborating Centre for Tuberculosis and Lung Diseases, Fondazione S. Maugeri, Tradate, Italy

5. Department of International Relations, Ministry of Health, Jerusalem, Israel

6. Braun School of Public Health, Hebrew University, Jerusalem, Israel

Citation style for this article:

Mor Z, Kolb H, Lidji M, Migliori GB, Leventhal A. Tuberculosis diagnostic delay and therapy outcomes of non-national migrants in Tel Aviv, 1998-2008 . Euro Surveill. 2013;18(12):pii=20433. Available online: http://www.eurosurveillance.org/ViewArticle.aspx?Articleld=20433

Article submitted on 09 July 2012/ published on 21 March 2013

Non-national migrants have limited access to medical therapy. This study compares diagnostic delay and treatment outcomes of non-insured non-national migrants (NINNM) with insured Israeli citizens (IC) in the Tel Aviv tuberculosis (TB) clinic between 1998 and 2008. Patient delay was the time from symptoms onset to doctor's visit, while system delay was measured from doctor visit to anti-TB therapy administration. We randomly sampled 222 NINNM and 265 IC. NINNM were younger than IC, had lower male to female ratio and fewer smoked. They had less drug/ alcohol abuse, more cavitations on chest radiography, longer patient and shorter system delay. Mean patient and system delays of all patients were $25 \pm 14$ and $79 \pm 42$ days, respectively. In multivariate analysis, being NINNM, asymptomatic or smoking predicted longer patient delay, while being asymptomatic or having additional co-morbidity predicted longer system delay. Treatment success in sputum smear-positive pulmonary TB NINNM was $81 \%$ and $95.7 \%$ in IC $(p=0.01)$. Treatment success was not associated with patient or system delay. In multivariate analysis, work security and treatment adherence predicted treatment success. NINNM had longer patient delay and worse therapy outcome, while IC had longer system delay. Both delays should be reduced. NINNM should be informed that TB therapy is free and unlinked with deportation.

\section{Introduction}

The global movement of people from less-resourced countries to more affluent and industrialised countries seeking work and improved living conditions has increased during the last decades [1]. Health authorities in many countries of destination are concerned with the potential importation of tuberculosis (TB) by migrants who originate in high TB prevalence areas [2], as it is estimated that about one third of them are infected with Mycobacterium tuberculosis, and approximately 5 to $10 \%$ of those infected will eventually develop active TB [3].
Undocumented migrants in the United States (US) and Europe are usually not medically insured and are most likely excluded from health services $[4,5]$. Nevertheless, most industrialised countries cover TB treatment costs for all non-national migrants (NNM), mainly to protect the citizens in the hosting countries from infection [6]. This approach is also being practiced in Israel, which has become a selected destination for labor migration since the early 1990ies.

Israel is a country of around eight million inhabitants, and it is estimated that 226,000 NNM presently stay in the country. The majority originate from low-resourced countries, characterised by a high TB burden [7]. Of all 6.2 million Jews living in Israel in 2011, 1.9 (30.1\%) were born outside Israel. Unlike NNM, Jewish homecomers to Israel are naturalised upon arrival and are never refused nor delayed, regardless of their health status, age, education or sex. They are also entitled to a comprehensive package of social, educational and financial benefits, including medical insurance from day one of their arrival, in order to accelerate their absorption into society. The policy of encouraging the migration of individuals of Jewish decent is one of the core values of the Israeli society, who is keen to assimilate the newcomers [8].

Most NNM live in Tel Aviv, which is the largest metropolis of Israel (1.3 million inhabitants), and functions as the commercial, cultural and social center for all NNM communities in Israel.

Documented NNM who hold a valid working visa are medically insured by their employer in private medical insurances as long as they are employed. Regretfully, in many instances when a NNM is diagnosed with TB, they lose their jobs, and the medical insurance companies tend to refrain from covering medical expenses, claiming that TB is an exacerbation of a prevailing medical condition. Undocumented NNM, who account for around half of all migrant workers in Israel, are not 
medically insured. The Israeli Ministry of Health reimburses TB clinics for treating both documented and undocumented NNM. In order to reduce barriers to medical treatment, therapy at the TB clinics is free and confidential, and patients are not reported to the immigration authorities or to their employers.

Diagnostic delay, comprised of patient and system delays, is an important determinant in TB control. Long diagnostic delay was found in Italy and Spain to result in more severe presentation and extensive disease, as well as an increased likelihood of TB transmission and elevated reproductive rate of TB in the community $[9,10]$. The aim of our study was to assess factors associated with diagnostic delay, and to compare diagnostic delay and treatment success between non-insured NNM (NINNM) and that of Israeli citizens (IC) in the Tel Aviv lung clinic. Our hypotheses was that NINNM will have longer diagnostic delays and worse treatment outcomes than IC, as they may not have access to most of the ambulatory services, and in addition they may (wrongly) perceive that their illness might be used by their employer to discharge them or lead to deportation.

\section{Methods}

In our retrospective study we compared a random sample of NINNM and IC who were older than 18 years of age and were treated in the Tel Aviv TB outpatient clinic for active TB between 1998 and 2008. The catchment area of the TB clinic includes Tel Aviv and central Israel, with a population of about two million people.

IC were either Israeli-born or born elsewhere and naturalised. Patients were excluded from the study if they were naturalised during the TB-treatment, and if they started or completed their treatment in another TB clinic.

\section{Definitions used}

A TB case was defined as a patient with pulmonary or extrapulmonary TB diagnosed by a pulmonologist specialised in TB, on the basis of clinical symptoms, and who additionally (i) had either direct sputum smear microscopy or culture positive for M. tuberculosis, and/ or (ii) was prescribed a full course of anti-TB drugs for a period longer than three months due to TB-related symptoms, or due to chest radiography findings.

Outcome variables were diagnostic delay, namely patient and system delay, as well as treatment success. Patient delay was defined as the time elapsed from the estimated date of onset of symptoms, as reported by the patients, to the first time they attended medical care with regard to those symptoms. System delay was defined as the time elapsed from the first medical visit with regard to the TB symptoms until initiation of antiTB therapy. Patient or system delays were categorised as 'long' if they were greater than the mean delay of all patients sampled. Treatment success was defined as patients who were cured or completed therapy, as classified by the World Health Organization (WHO) guidelines [11].

Independent variables for diagnostic delay and treatment success included sex, country of birth, citizenship, length of stay in Israel, TB site, smoking, drug or alcohol use, employment status, human immunodeficiency virus (HIV) infection, any underlying chronic disease, and sputum smear, culture and drug susceptibility results.

Continuous variables were presented by means and standard deviations (SD). Comparisons between groups were made using the chi-square or Fisher's exact test for categorical variables and Student's $t$-test for continuous attributes distributed normally or the Mann-Whitney test for variables whose distribution was not normal. All $p$-values reported are based on two-tailed comparisons with statistical significance set at p<0.05. Variables which were found significant in the bivariate analysis, and after assessing for collinearity, were entered the multivariate analysis performed by the logistic regression model. The statistical package SPSS (17.0 version for Windows, Chicago, IL, USA) was used for the analyses.

Ethical approval was granted from the Institutional Review Board of E. Wolfson hospital, Holon, Israel.

\section{Results}

Between January 1998 and December 2008, 355 NINNM (23.7\%) and 1,139 (76.3\%) IC TB patients were treated in the Tel Aviv TB clinic, while 222 and 265 of these respectively, were included in the study. The male to female ratio and rate of NINNM to IC in the total sample was not significantly different than that of those who were not selected $(p=0.06$ and $p=0.17$, respectively), yet the average age of the sample was 2.3 years younger that of the patients who were not selected $(p=0.03)$.

NINNM were diagnosed with TB 3.1 \pm 2.7 years following their arrival in Israel, and the IC $(n=165,62.5 \%$ of all IC) who were born outside Israel were diagnosed $23 \pm 17$ years after their arrival (p<0.01). Of all NINNM, $109(49.1 \%)$ were born in south-east Asia, $49(22.1 \%)$ in Africa, 39 (17.6\%) in eastern Europe, $13(5.9 \%)$ in south America and $12(5.3 \%)$ in the middle east.

NINNM were younger than IC, were more often females, were more likely to originate in high TB burden countries, and to be employed while diagnosed. They were less likely to smoke or be drug/alcohol dependent and had less chronic diseases (Table 1). The proportion of extrapulmonary TB cases among all TB cases in NINNM did not differ from that in IC. NINNM were more likely to have cavitations on chest radiography than IC and had more sputum smear positive, were hospitalised for longer periods and had longer patient delay and shorter system delay. No differences were found in the 
TABLE 1

Characteristics of patients included in study, Tel Aviv tuberculosis clinic, 1998-2008 (n=487)

\begin{tabular}{|c|c|c|c|c|}
\hline \multicolumn{2}{|l|}{ Characteristic } & $\begin{array}{c}\text { Non-insured non- } \\
\text { national migrant } \mathrm{N}=222 \\
\mathrm{n}(\%)^{\mathrm{a}}\end{array}$ & $\begin{array}{l}\text { Israeli citizen } \\
\mathrm{N}=265 \\
\mathrm{n}(\%)^{\mathrm{a}}\end{array}$ & $\mathrm{p}$ value \\
\hline \multicolumn{2}{|c|}{ Age at diagnosis (years, SD) } & $35.0 \pm 9.8$ & $53.7 \pm 19.7$ & $<0.01$ \\
\hline \multicolumn{2}{|l|}{ Male sex } & $101(45.5)$ & $161(60.8)$ & 0.01 \\
\hline \multicolumn{2}{|c|}{ Originating in high TB prevalence area ${ }^{\mathrm{b}}$} & $213(95.9)$ & $155(58.5)$ & $<0.01$ \\
\hline \multicolumn{2}{|c|}{ Employed while diagnosed } & $175(78.8)$ & $75(28.3)$ & $<0.01$ \\
\hline \multicolumn{2}{|l|}{ Substance abuse ${ }^{c}$} & $4(1.8)$ & $22(8.3)$ & 0.02 \\
\hline \multicolumn{2}{|c|}{ Previous TB diagnosis } & $13(5.9)$ & $50(18.9)$ & $<0.01$ \\
\hline \multicolumn{2}{|c|}{ Any underling chronic disease } & $23(10.4)$ & $103(38.9)$ & $<0.01$ \\
\hline \multicolumn{2}{|l|}{ Smoking ${ }^{c}$} & $22(9.9)$ & $92(34.7)$ & $<0.01$ \\
\hline \multicolumn{2}{|l|}{ HIV infection } & $11(5.0)$ & $5(1.9)$ & 0.07 \\
\hline \multicolumn{2}{|c|}{ Mean time from arrival in Israel to TB diagnosis (years, SD) } & $3.1 \pm 2.7$ & $23 \pm 17$ & $<0.01$ \\
\hline \multicolumn{2}{|c|}{ Any symptom related to $\mathrm{TB}^{\mathrm{d}}$} & $161(72.5)$ & $193(72.8)$ & 1 \\
\hline \multicolumn{2}{|l|}{ Pulmonary TB } & $158(71.2)$ & $191(72.1)$ & 0.8 \\
\hline \multicolumn{2}{|c|}{ Pulmonary TB in patients residing in Israel $<5$ years } & $128(57.6)$ & $47(17.7)$ & 0.02 \\
\hline \multirow{5}{*}{$\begin{array}{l}\text { Extrapulmonary } \\
\text { TB site }\end{array}$} & Pleura $^{e}$ & $14(24.4)$ & $21(29.5)$ & 0.3 \\
\hline & Lymph nodese,f & $36(58.5)$ & $12(21.6)$ & $<0.01$ \\
\hline & Urogenitale $^{\mathrm{e}}$ & $3(3.7)$ & $19(21.6)$ & $<0.01$ \\
\hline & Musculoskeletal ${ }^{\mathrm{e}}$ & $2(2.4)$ & $6(6.8)$ & 0.1 \\
\hline & Other sites ${ }^{e}$ & $9(11.1)$ & $18(20.5)$ & 0.07 \\
\hline \multicolumn{2}{|c|}{ Cavitations in chest radiography ${ }^{g}$} & $67(42.4)$ & $46(24.1)$ & $<0.01$ \\
\hline \multicolumn{2}{|c|}{ Sputum smear-positive ${ }^{g}$} & $79(50.0)$ & $70(36.6)$ & 0.04 \\
\hline \multicolumn{2}{|l|}{ Culture-positive $^{g}$} & $106(67.1)$ & $109(57.1)$ & 0.05 \\
\hline \multicolumn{2}{|c|}{ Resistant to any first-line anti-TB drug ${ }^{\mathrm{h}}$} & $34(21.5)$ & $30(15.7)$ & 0.1 \\
\hline \multicolumn{2}{|c|}{ Multidrug resistance } & $4(2.5)$ & $8(4.2)$ & 0.3 \\
\hline \multicolumn{2}{|c|}{ Hospitalised due to TB } & $94(42.3)$ & $114(43.0)$ & 0.9 \\
\hline \multicolumn{2}{|c|}{ Length of hospitalisation (weeks) } & $9.9 \pm 5.9$ & $7.6 \pm 7.5$ & 0.04 \\
\hline \multicolumn{2}{|c|}{ DOT adherence $>80 \%$ for six months of treatment } & $192(86.5)$ & $229(86.4)$ & 0.5 \\
\hline \multicolumn{2}{|c|}{ Treatment success ${ }^{i}$} & $185(83.3)$ & $241(90.9)$ & 0.01 \\
\hline \multicolumn{2}{|c|}{ Mean patient delay (days, SD) } & $33.1 \pm 3.6$ & $18.6 \pm 2.8$ & 0.01 \\
\hline \multicolumn{2}{|c|}{ Mean system delay (days, SD) } & $48.9 \pm 5.3$ & $105.3 \pm 11.1$ & $<0.01$ \\
\hline
\end{tabular}

Percentages were calculated on the basis of the number of cases for which information was available.

DOT: directly observed treatment; HIV: human immunodeficiency virus; SD: standard deviation; TB: tuberculosis.

a Unless otherwise specified.

b Above 20 cases per 100,000 population.

c Present or past.

d Cough longer than three weeks, haemopthysis, chest pain, sub-febrile teperature, weight loss, night sweats.

e In extrapulmonary tuberculosis patients.

f If there were multiple sites, the site other than the peripheral lymph node was considered the principle site.

g In pulmonary tuberculosis patients.

h Isoniazid, rifampicin, ethambutol, pyrazinamide.

i Patients who were cured or whose treatment was completed. 


\begin{tabular}{|c|c|c|c|c|c|c|c|}
\hline \multirow{2}{*}{\multicolumn{2}{|c|}{ Characteristic }} & \multicolumn{3}{|c|}{ Patient delay (mean $25 \pm 14$ days) } & \multicolumn{3}{|c|}{ System delay (mean $79 \pm 42$ days) } \\
\hline & & $\begin{array}{c}\text { Below the mean } \\
\begin{array}{c}\mathrm{N}=316 \\
\mathrm{n}(\%)^{\mathrm{a}}\end{array}\end{array}$ & $\begin{array}{c}\text { Above the } \\
\text { mean } N=171 \\
n(\%)^{\mathrm{a}}\end{array}$ & $p$ value & $\begin{array}{c}\text { Below the } \\
\text { mean } N=282 \\
n(\%)^{a}\end{array}$ & $\begin{array}{c}\text { Above the } \\
\text { mean } N=205 \\
n(\%)^{\mathrm{a}}\end{array}$ & $p$ value \\
\hline \multicolumn{2}{|c|}{ Age at diagnosis (years, SD) } & $43.5 \pm 17.7$ & $48.1 \pm 13.2$ & 0.02 & $47.5 \pm 19.3$ & $41.6 \pm 16.5$ & 0.01 \\
\hline \multicolumn{2}{|l|}{ Male sex } & $171(54.1)$ & $80(46.7)$ & 0.2 & $156(55 \cdot 3)$ & $108(52.7)$ & 0.6 \\
\hline \multicolumn{2}{|c|}{ Non-insured non-national migrant } & $114(36.1)$ & $96(56.1)$ & $<0.01$ & $139(49.3)$ & $74(36.1)$ & $<0.01$ \\
\hline \multicolumn{2}{|c|}{ Originating in high TB prevalence areab } & $218(70.0)$ & $145(84.8)$ & $<0.01$ & $212(75.2)$ & $154(75.1)$ & 0.2 \\
\hline \multicolumn{2}{|c|}{ Years from arrival to Israel $^{c}$} & $15.6 \pm 19.1$ & $9.1 \pm 15.1$ & 0.01 & $12.1 \pm 17.5$ & $14 \cdot 5 \pm 18.8$ & 0.2 \\
\hline \multicolumn{2}{|c|}{ Employed while diagnosed } & $148(46.8)$ & $92(53.8)$ & 0.01 & $146(51.8)$ & $93(45.3)$ & 0.07 \\
\hline \multicolumn{2}{|c|}{ Substance abuse $^{d}$} & $14(4.6)$ & $11(6.4)$ & 0.39 & $14(4.9)$ & $11(5.4)$ & 1 \\
\hline \multicolumn{2}{|c|}{ Previous TB diagnosis } & $45(14.2)$ & $18(10.5)$ & 0.4 & $39(13.8)$ & $24(11.7)$ & 0.5 \\
\hline \multicolumn{2}{|c|}{ Any underlying chronic disease } & $87(27.5)$ & $37(21.6)$ & 0.3 & $60(21.3)$ & $66(32.5)$ & $<0.01$ \\
\hline \multicolumn{2}{|l|}{ Smoking ${ }^{d}$} & $86(27.2)$ & $23(13.4)$ & $<0.01$ & $52(18.4)$ & $56(27.3)$ & 0.05 \\
\hline \multicolumn{2}{|l|}{ HIV infection } & $10(3.1)$ & $6(3.5)$ & 0.8 & $8(1.8)$ & $8(3.9)$ & 0.6 \\
\hline \multicolumn{2}{|c|}{ Any symptom related to $\mathrm{TB}^{\mathrm{e}}$} & $208(65.8)$ & $26(15.2)$ & $<0.01$ & $182(64.5)$ & 39 (19.1) & $<0.01$ \\
\hline \multirow{3}{*}{$\begin{array}{l}\text { Referral to TB } \\
\text { clinic by }\end{array}$} & Self referral/ & $\mathrm{N} / \mathrm{A}$ & $\mathrm{N} / \mathrm{A}$ & $\mathrm{N} / \mathrm{A}$ & $5(2.0)$ & $0(0.0)$ & $<0.01$ \\
\hline & Screening & $\mathrm{N} / \mathrm{A}$ & $\mathrm{N} / \mathrm{A}$ & $\mathrm{N} / \mathrm{A}$ & $188(72.3)$ & $109(53.7)$ & $\mathrm{N} / \mathrm{A}$ \\
\hline & General practitioner & $\mathrm{N} / \mathrm{A}$ & $\mathrm{N} / \mathrm{A}$ & $\mathrm{N} / \mathrm{A}$ & $67(25)$ & $94(45.8)$ & $\mathrm{N} / \mathrm{A}$ \\
\hline \multicolumn{2}{|c|}{ Extrapulmonary TB } & $83(26.2)$ & $50(29.2)$ & 0.39 & $74(26.2)$ & $57(27.8)$ & 1 \\
\hline \multicolumn{2}{|c|}{ Cavitations in chest radiography } & $24(7.2)$ & $17(9.9)$ & 0.01 & $28(9.9)$ & $13(6.4)$ & 0.26 \\
\hline \multicolumn{2}{|c|}{ Sputum smear-positive $^{f}$} & $96(30.4)$ & $82(47.9)$ & 0.04 & $89(31.5)$ & $78(38.0)$ & 0.2 \\
\hline \multicolumn{2}{|c|}{ Culture-positive $^{f}$} & $168(53.2)$ & $94(55.0)$ & 0.14 & $133(47.2)$ & $130(63.4)$ & $<0.01$ \\
\hline \multicolumn{2}{|c|}{ Resistant to any first line anti-TB drug ${ }^{g}$} & $38(12.0)$ & $25(14.6)$ & 0.7 & $30(10.6)$ & $33(16.1)$ & 0.6 \\
\hline \multicolumn{2}{|c|}{ Multidrug resistance } & $7(2.2)$ & $5(2.9)$ & 0.7 & $4(1.4)$ & $8(3.9)$ & 0.29 \\
\hline \multicolumn{2}{|c|}{ Hospitalised due to TB } & $116(36.7)$ & $87(50.9)$ & 0.01 & $101(35.8)$ & $103(50.2)$ & 0.01 \\
\hline
\end{tabular}

HIV: human immunodeficiency virus; SD: standard deviation; TB: tuberculosis.

a Unless otherwise specified

b Above 20 cases per 100,000 population.

c For patients not born in Israel.

d Present or past.

e Cough longer than three weeks, haemopthysis, chest pain, sub-febrile teperature, weight loss, night sweats.

In pulmonary tuberculosis patients.

g Isoniazid, rifampicin, ethambutol, pyrazinamide.

rate of multidrug resistance or any single drug resistance between the two groups.

The mean patient delay for all patients in our study was $25 \pm 14$ days and mean system delay was $79 \pm 42$ days ( $p<0.01)$. Longer than average patient delay was more common in older patients, NINNM, those originating from high TB burden countries or who spent fewer years in Israel, those who did not smoke, and patients who were less symptomatic (Table 2). Additionally, those who had longer patient delay also had more cavitations on chest radiography and were more often sputum smear positive or hospitalised for a longer period than those who had shorter than average patient delay. Patients with longer than average system delay were younger, more often IC, had more underlying chronic disease, were more often smokers and had less TB symptoms.

Multivariate analysis suggested that being a NINNM, asymptomatic or a smoker are factors predicting longer patient delay; while being asymptomatic or having an underlying chronic disease are predicting factors for longer system delay (Table 3).

The rate of treatment success of the entire study population was $87.5 \%$ (426/487). Among patients with sputum smear-positive pulmonary TB, $81 \%(64 / 79)$ of the NINNM and $95.7 \%(67 / 70)$ of the IC achieved treatment success, $p=0.01$. Patients whose treatment outcome 
TABLE 3

Multiple logistic regression analysis of the factors associated with patient and system delay for patients included in study, Tel Aviv tuberculosis clinic, 1998-2008 ( $\mathrm{n}=487)$

\begin{tabular}{|c|c|c|c|c|}
\hline \multirow{2}{*}{ Characteristic } & \multicolumn{2}{|c|}{ Patient delay } & \multicolumn{2}{|c|}{ System delay } \\
\hline & $p$ value & OR $(95 \% \mathrm{Cl})$ & $\mathrm{p}$ value & OR $(95 \% \mathrm{Cl})$ \\
\hline Age at diagnosis & 0.9 & $1.0(0.9-1.1)$ & 0.4 & $1.0(0.9-1.1)$ \\
\hline Non-insured non-national migrants & 0.01 & $3.5(1.3-9.5)$ & 0.8 & $0.5(0.2-1.1)$ \\
\hline Asymptomatic & 0.01 & $1.3(1.2-1.8)$ & 0.02 & $1.6(2.3-3.5)$ \\
\hline Originating from a high TB prevalence area ${ }^{a}$ & 0.7 & $0.9(0.3-3.3)$ & N/A & N/A \\
\hline Employed while diagnosed & 0.5 & $0.7(0.3-1.9)$ & N/A & $\mathrm{N} / \mathrm{A}$ \\
\hline Smoking ${ }^{b}$ & 0.01 & $2.5(1.2-5.0)$ & N/A & N/A \\
\hline Cavitations on chest radiography & 0.8 & $0.9(0.9-1.1)$ & N/A & $\mathrm{N} / \mathrm{A}$ \\
\hline Any underlying chronic disease & N/A & N/A & 0.03 & $2.4(1.1-5.2)$ \\
\hline Culture-positive & N/A & $\mathrm{N} / \mathrm{A}$ & 0.1 & $1.7(0.9-3.3)$ \\
\hline Hospitalisation due to TB & N/A & N/A & 0.1 & $0.6(0.3-1.2)$ \\
\hline
\end{tabular}

$\mathrm{Cl}$ : confidence interval; N/A: nNot applicable; OR: odds ratio, TB: tuberculosis.

a Above 20 cases per 100,000 population.

b Present or past.

TABLE 4

Treatment success for patients included in study, Tel Aviv tuberculosis clinic, 1998-2008 ( $\mathrm{n}=487)$

\begin{tabular}{|c|c|c|c|}
\hline Characteristic & $\begin{array}{c}\text { Success } N=426 \\
n(\%)^{\mathrm{a}}\end{array}$ & $\begin{array}{c}\text { No success } N=61 \\
n(\%)^{\mathrm{a}}\end{array}$ & $\mathrm{p}$ value \\
\hline Age at diagnosis (years, SD) & $45 \pm 18.01$ & $46.63 \pm 21.5$ & 0.52 \\
\hline Male sex & $230(54.0)$ & $32(52.5)$ & 0.89 \\
\hline Israeli citizen & $241(56.6)$ & $24(39.3)$ & 0.01 \\
\hline Originating in a high TB prevalence areab & $97(22.8)$ & $12(19.7)$ & 0.74 \\
\hline Employed while diagnosed & $217(50.9)$ & $33(54.1)$ & 0.63 \\
\hline Substance abuse ${ }^{c}$ & $21(4.9)$ & $5(8.2)$ & 0.35 \\
\hline Any underling chronic disease & $107(25.1)$ & $19(31.1)$ & 0.43 \\
\hline Smoking ${ }^{c}$ & $99(23.2)$ & $15(24.6)$ & 0.87 \\
\hline HIV infection & $9(2.1)$ & $7(11.5)$ & 0.02 \\
\hline Any symptom related to $\mathrm{TB}^{\mathrm{d}}$ & $310(72.8)$ & $44(72.1)$ & 1 \\
\hline Pulmonary TB & $312(73.2)$ & $37(60.7)$ & 0.04 \\
\hline Resistant to any first line anti-TB druge & $53(24.4)$ & $11(18.0)$ & 0.11 \\
\hline Multidrug resistance & $10(2.3)$ & $2(3.2)$ & 0.646 \\
\hline Lost job due to TB diagnosis ${ }^{f}$ & 28 (12.9) & $16(48.5)$ & $<0.01$ \\
\hline DOT adherence $>80 \%$ for six months of treatment & $398(93.4)$ & $23(37.7)$ & $<0.01$ \\
\hline Patient delay (days \pm SD) & $25.6 \pm 2.5$ & $20.7 \pm 5.0$ & 0.48 \\
\hline System delay (days \pm SD) & $80.4 \pm 7.3$ & $73.7 \pm 12.6$ & 0.75 \\
\hline
\end{tabular}

DOT: directly observed treatment; HIV: human immunodeficiency virus; SD: standard deviation; TB: tuberculosis.

a Unless otherwise specified

b Above 20 cases per 100,000 population.

Present or past.

d Cough longer than three weeks, haemopthysis, chest pain, sub-febrile teperature, weight loss, night sweats.

e Isoniazid, rifampicin, ethambutol, pyrazinamide.

f Of all patients employed while diagnosed with tuberculosis.

Treatment success was defined as patients who were cured or completed therapy, as classified by the WHO guidelines [12]. 


\section{TABLE 5}

Multiple logistic regression analysis of the factors associated with treatment success, for patients included in study, Tel Aviv tuberculosis clinic, 1998-2008 (n=487)

\begin{tabular}{|l|c|c|}
\hline & p value & $\begin{array}{c}\text { OR } \\
(95 \% \mathrm{Cl})\end{array}$ \\
\hline Israeli citizenship & 0.8 & $\begin{array}{c}1.08 \\
(0.4-2.9)\end{array}$ \\
\hline HIV infection & 0.4 & $\begin{array}{c}0.4 \\
(0.05-3.0)\end{array}$ \\
\hline Pulmonary TB & 0.1 & $\begin{array}{c}0.49 \\
(0.2-1.3)\end{array}$ \\
\hline $\begin{array}{l}\text { Employment sustained } \\
\text { (was not discharged) }\end{array}$ & $<0.01$ & $\begin{array}{c}7.65 \\
(2.6-22.7)\end{array}$ \\
\hline $\begin{array}{l}\text { DOT adherence >80\% for } \\
\text { six months of treatment }\end{array}$ & $<0.01$ & $\begin{array}{c}11.2 \\
(3.6-36.6)\end{array}$ \\
\hline
\end{tabular}

$\mathrm{Cl}$ : confidence interval; DOT: directly observed treatment; HIV: human immunodeficiency virus; OR: odds ratio; TB: tuberculosis.

Treatment success was defined as patients who were cured or completed therapy, as classified by the WHO guidelines [12].

was successful were more commonly IC, HIV-free, had pulmonary TB, kept their jobs during their illness and adhered to the regimen of directly observed therapy (DOT) (Table 4).

Multivariate analysis suggested that having work secured during illness and adherence to DOT are predictors for treatment success (Table 5 ).

\section{Discussion}

Patient delay in this study was longer in NINNM and system delay was longer in IC. The rates of TB treatment success after six months of therapy were inferior in NINNM compared to IC.

NINNM in our study were younger and had better health determinants than IC, similar to findings published earlier in Canada and the US [12,13]. This phenomenon is labeled as the 'healthy migrant effect', and points to the self-selection of healthier and better prepared individuals to overcome the difficulties pertaining to migration [11]. The majority of the IC in our study were born in high TB burden areas and they were older and had stayed in Israel for a longer time than NINNM. Given that Israel is a low TB prevalence country, those IC diagnosed with TB who were born outside Israel were probably infected in their countries of origin before they immigrated to Israel. It is assumed that they developed active TB due to weakening of their immune system, older age, or other concomitant underlying medical conditions.
Although there is no consensus to what length a diagnostic delay is accepted [14], the patient delay in our study and the system delay in NINNM were within the limits of timeframes published from Italy and Spain $[10,14,15]$, yet system delay among IC was much longer, corresponding to findings in a study from Taiwan reporting on system delay in Taiwanese nationals [16]. The majority of IC in our study were older than NINNM and had underlying chronic diseases that might have masked TB symptoms. In our own experience, IC patients usually consult their family physician during the initial stage of their disease, however, the low TB incidence among IC might lead physicians to reduce their index of suspicion regarding the possibility of TB diagnosis. The physicians probably order other tests rather than TB-diagnostic procedures. Cough was found to be a significant complaint associated with system delay among citizens in Brazil, reducing healthcare providers' sensitivity to the possibility of TB, as cough is a symptom for many other respiratory diseases as well [17]. NINNM often consult one of the two general free outpatient clinics in Tel Aviv designated for non-insured patients. Healthcare providers in these clinics are familiar with the specific medical conditions of migrants and are more sensitive to the possibility of TB diagnosis than general physicians in clinics serving IC, and thus generally refer patients to the free TB clinic in a relatively timely manner.

NINNM had longer patient delay than IC, as also found in Italy [14], possibly due to a combination of reasons: lack of medical insurance, non-acquaintance with availability of free TB services, or the efforts necessary to commute to the clinic. Additionally, fear of deportation or discontinuation of their employment and other or social barriers may hinder the migrants of using the available TB services [18]. The outcome of presenting late at a physician was demonstrated in our study. It resulted in a more extensive disease, greater rates of positive smear results and the presence of cavitations on chest radiographs among the NINNM. It may also explain the need for longer hospitalisation for NINNM, possibly because their disease was more progressive and their living conditions did not allow for domestic isolation in the community.

Extrapulmonary TB patients had longer system delay. A possible explanation for this is that the symptoms are often diffuse and non-specific which renders the medical process of differential diagnosis more difficult, and probably leads the physician to search for other causes. Although extra pulmonary TB is seldom infectious, delay in diagnosis may increase morbidity and mortality $[10,19]$.

Treatment success rate in the Tel Aviv TB clinic for the study period was higher than the WHO goal of $85 \%$ [20]. Although citizenship was not found to be a variable predicting treatment success by the regression model, IC had better treatment outcome than NINNM in the univariate analysis. Most NINNM who did not reach 
treatment success were 'transferred out' or 'defaulted from therapy' (data not presented), as they either left Israel at their own discretion or that treatment demands of more than six months of therapy made it impossible for them to combine their work duties with clinic visits. It is noteworthy that employment security was a significant predictive determinant for treatment success in our study. Nevertheless, longer patient or system delays were not found to be associated with treatment success, and it may be that the clinics' outreach efforts for the patients and supporting them in completing treatment, regardless of the severity of the disease, had a positive impact on adherence.

This study is subject to limitations on recall bias, due to the retrospective approach of data collection with resulting uncertainty of the actual onset of symptoms, as well as linguistic and cultural gaps which might limit the effectiveness of the medical interview performed by the physician. However, data were collected in a similar fashion for IC and NINNM alike, and the bias, if it exists, is non-differential and conservative. Additionally, due to the retrospective nature of the study, other determinants such as homelessness, income, education and other health perception attributes could not be ascertained. We also were not able to define whether patients were infected in Israel or acquired the infection in their country of origin, and reactivated in Israel. Finally, the generalisation of the study results to all NNM in Israel may be questionable. Yet, most of the migrant workers, especially those noninsured, reside in Tel Aviv.

\section{Conclusions}

NINNM in our study had longer patient delay, while IC had longer system delay. Both delays should be reduced. As many industrialised countries in Europe host migrants, our finding may be valid for organisations providing healthcare for migrants. Health professionals should use the opportunity of TB screenings where performed, to inform migrants about the possibility that TB may develop in later stages, and discuss with them about typical TB symptoms. NINNM in Israel should also be advised about possibilities of free TB treatment, and that care is independent of deportation regulations. Additionally, it would be desirable to establish a system of employment security to counteract the economic instability and to loss of income of NINNM infected with TB. In order to ensure treatment completion, NINNM who return to work at the final stages of their treatment should be provided DOT in a flexible approach, by costumising the time and place to make it convenient for the patients, and possibly with financial incentives for them to complete treatment and adhere to follow-up. Finally, primary care physicians should be informed that TB diagnosis in IC is possible, to increase their index of suspicion.
Acknowledgements

The authors are grateful to Dr. Nira Koren Morag, Tel Aviv University, for her exceptional statistical advices and analyses and for Ms. Judy Brandt, E. Wolfson Medical Center, for editorial assistance.

The study was partially supported by the Israeli Lung Association Tel Aviv. 


\section{References}

1. International Organization of Migration (IOM). World migration report 2010. Geneva: IOM; 2011. Available from: http:// publications.iom.int/bookstore/free/WMR2010_summary.pdf.

2. Falzon D, van Cauteren D. Demographic features and trends in tuberculosis cases in the European Region, 1995-2005. Euro Surveill. 2008;13(12): pii=8075. Available from: http://www. eurosurveillance.org/ViewArticle.aspx?Articleld=8075

3. Horsburgh CR Jr. Priorities for the treatment of latent tuberculosis infection in the United States. N Eng Med. 2004;350(20):2060-7. http://dx.doi.org/10.1056/ NEJMsa031667. PMid:15141044

4. Centres for Disease Control and Prevention (CDC). Trends in tuberculosis- United States, 2007. MMWR Morb Mortal Wkly Rep. 2008;57(11):281-5.

5. Dara M, de Colombani P, Petrova-Benedict R, Centis R, Zellweger JP, Sandgren A, et al. The minimum package from cross-border control and care in the WHO European region: a Wolfheze consensus statement. Eur Respir J 2012;40(5):108190. http://dx.doi.org/10.1183/09031936.00053012 PMid:22653772 PMCid:3485571

6. Heldal E, Kuyvenhoven JV, Wares F, Migliori GB, Ditiu L, Fernandez de la Hoz K, et al. Diagnosis and treatment of tuberculosis in undocumented migrants in low- or intermediate-incidence countries. Int J Tuberc Lung Dis. 2008;12(8):878-88. PMid:18647446

7. Population, immigration and Border Authority. Data on foreigners in Israel. Jul 2011. Hebrew. Available from: http:// www.piba.gov.il/PublicationAndTender/ForeignWorkersStat/ Documents/july2011.pdf.

8. Mor Z, Lerman Y, Leventhal A. Pre-immigration screening process and pulmonary tuberculosis among Ethiopian migrants in Israel. Eur Respir J. 2008;32(2):413-8. http://dx.doi. org/10.1183/09031936.00145907 PMid:18385171

9. Diez MJ, Bleda MJ, Alcaide J, Caloto T, Castells C, Cardenal JI, et al. Determinants of patient delay among tuberculosis case in Spain. Eur J Pub Health. 2005; 343-9. PMid:16014664

10. Strola DG, Yimer S, Bjune GA. A systematic review of delay and treatment of tuberculosis. BMC Public Health. 2008; 8:15 http://dx.doi.org/10.1186/1471-2458-8-15 PMid:18194573 PMCid:2265684

11. Veen J, Raviglione M, Rieder HL, Migliori GB, Graf P, Grzemska $M$, et al. Standardized tuberculosis treatment outcome monitoring in Europe. Recommendations of a Working Group of the World Health organization (WHO) and the European Region of the International Union against Tuberculosis and Lung Disease (IUATLD) for uniform reporting by cohort analysis of treatment outcome in tuberculosis patients. Eur Respir J. 1998;12(2):505-10. http://dx.doi.org/10.1183/09031936.98.120 20505 PMid:9727811

12. Ali JS, McDermott S, Gravel RG. Recent research on immigrants health from statistics Canada's population surveys. Can J Public Health. 2004;95(3):I9-13. PMid:15191126

13. Achkar JM, Sherpa T, Cohen HW, Holzman RS. Differences in clinical presentation among persons with pulmonary tuberculosis: A comparison of documented and undocumented foreign born versus US-born persons. Clin Infect Dis. 2008;47(10):1277-83. http://dx.doi.org/10.1086/592572 PMid:18834320 PMCid:2746906

14. Gagliotti C, Resi D, Moro ML. Delay in the treatment of pulmonary TB in a changing demographic scenario. Int J Tuberc Lung Dis. 2006;10(3):305-9. PMid:16562711

15. Sanz B, Blasco T; ATBIM Project. Variables associated with diagnostic delay in immigrant groups with tuberculosis in Madrid. Int J Tuberc Lung Dis. 2007;11(6): 639-46. PMid:17519095

16. Lin HP, Deng CY, Chou P. Diagnosis and treatment delay among pulmonary tuberculosis patients identified using the Taiwan reporting enquiry system, 2002-2006. BMC Public Health. 2009; 9:55. http://dx.doi.org/10.1186/1471-2458-9-55 PMid:19216733 PMCid:2654887

17. Machado AC, Steffen RE, Oxlade 0, Menzies D, Kritski A, Trajman A. Factors associated with delayed diagnosis of pulmonary tuberculosis in the state of Rio de Janeiro, Brazil. J Bras Pneumol. 2011;37(4):512-20. http://dx.doi.org/10.1590/ S1806-37132011000400014 PMid:21881742

18. Tala E. Tuberculosis care in foreigners: ethical considerations. Eur Respir J. 1994:7(8):1395-6. http://dx.doi.org/10.1183/09031 936.94.07081395 PMid:7957824

19. Sagbakken M, Bjune GA, Frich JC. Experience of being diagnosed with tuberculosis among immigrants in NorwayFactors associated with diagnostic delay: A qualitative study. Scand J Public Health. 2010;38(3):283-90. http://dx.doi. org/10.1177/1403494809357101 PMid:20056784
20. World Health Organization (WHO); International Union Against Tuberculosis and Lung Disease (IUATLD); Royal Netherlands Tuberculosis Association (KNCV). Revised international definition in tuberculosis control. Int J Tuberc Lung Dis. 2001;5(3):213-5. PMid:11326818 